\title{
AQUAPONICS MODEL SPECIFIC TO SOUTH AFRICAN CONDITIONS
}

\author{
Mchunu, N. ${ }^{1}$, Lagerwall, G. and Senzanje, A. \\ Correspondence author: N. Mchunu. Email: ntobeko.mchunuu@gmail.com
}

\begin{abstract}
Aquaponics is the integration of aquaculture (fish) and hydroponic culture (plants) as one system. Aquaponics requires a sound simultaneous understanding of two agricultural ecosystems (fish and plants) in order to have a viable system. Modelling and model development is sacrosanct in systems where productivity is uncertain or complex. The study was conducted in 2016 to collect aquaponics information in the Republic of South Africa (RSA) using an online survey questionnaire to determine local aquaponics uses, management and distribution. A total of 44 aquaponics operators were captured within three months (September-November) in 2016. In this study, it was shown and concluded that most aquaponics practitioners in RSA do not have adequate knowledge and skills in aquaponics production and management, and that development of the localised aquaponics model is important for South Africa. As a result, the aim of this study was to develop a model that is more specific to South African conditions in order to help South Africans to have a better opportunity to establish and operate aquaponic systems. This study was designed as a mixed approach combining different methods and sources of data to develop the model. Unified Modelling Language (UML), Microsoft excel, an online survey, observations, structured and unstructured interviews and content data were used. The developed model was able to predict the main aquaponics inputs variables, namely fish stocking density, daily fish feed, and required planting area. The fit for each of these variables was good to average with $R=0.7477$, 0.6957 , and 0.4313 respectively. There were no significant differences $(P<0.05)$ between the observed and simulated data for all variables (fish stocking density, daily fish and planting area variables). Therefore, it was concluded that this model can be adopted by aquaponics practitioners in RSA and extension officers or facilitators as an aquaponics start-up platform.
\end{abstract}

Keywords: Fish stocking density, daily fish feed, plant growing area, aquaponics model

\section{INTRODUCTION}

Agricultural extension is the application of scientific research and knowledge to agricultural practices through farmer education (Ministry of Agriculture Food Security and Cooperatives, 2006). In practice, agricultural extension could be described as the delivery of information inputs to farmers, particularly small-scale farmers (Food and Agricultural Organisation (FAO), 2015). Aquaponics (aquaponic systems) refers to the production of fish and vegetables at the same time through linking aquacultural fish waste to hydroponically growing plants as a natural nutrient source material (Goddek et al., 2015). In return, the plants clean and purify the water to maintain fish health in the fish tank (Turcios \& Papenbrock, 2014). Worldwide, the adoption of aquaponics is small and limited (Love et al., 2014; Love et al., 2015). Aquaponics has a related benefit of food security and economic productivity (Ibironke, 2013).

\footnotetext{
${ }^{1}$ Bioresources Engineering, School of Engineering, University of KwaZulu-Natal, P. Bag X01, Scottsville 3209, Pietermaritzburg, Republic of South Africa.
} 
S. Afr. J. Agric. Ext.

Vol. 47 No. 1, 2019: 73 - 91

http://dx.doi.org/10.17159/2413-3221/2019/v47n1a491
Mchunu, Lagerwall \&

Senzanje

(License: CC BY 4.0)

However, aquaponics has also been shown to be a complex system because fish have different nutrient requirement to that of plants. Thus, balancing the amount of fish feed to accommodate the plants' nutrient needs in a given area of hydroponic culture is often a problem (Lennard, 2012). This is mainly because it is a difficult procedure, particularly for ordinary people, this is shown and proven by two empirical approaches of addressing nutrient flow in aquaponics conducted by Rakocy (1989) and Lennard (2012) aquaponics solution. Both these approaches agreed that fish feed does not contain enough quantities of phosphorous $(\mathrm{P})$, potassium $(\mathrm{K})$, calcium $(\mathrm{Ca})$, and iron $(\mathrm{Fe})$. As a result, when one tries to balance one of these nutrients, other nutrients, particularly nitrogen, reaches a toxic level if left for a while. In addition, there is a microbial component which is most important because it is usually ignored by most aquaponics practitioners (Rakocy, 1989). The microbial component is responsible for the nitrogen transformation process, a process that triggers water to be cleansed by plants by transforming ammonia into a nitrate form suitable for plant uptake (Mchunu, Odindo \& Muchaonyerwa, 2018).

Furthermore, aquaponics requires a sound simultaneous understanding of two different agricultural ecosystems, namely morphological and physiological (Love et al., 2014; Love et al., 2015). Hence, aquaponics can be very complex and sometimes impossible where there is a lack of expertise. Moreover, it is well documented that fresh water pond aquaculture has nearly collapsed in the Republic of South Africa (RSA), predominantly because average outside environmental conditions do not accommodate fish to independently establish a viable economic population (Swap et al., 2002).

Modelling is the simplified representation of a real system such as aquaponics. Models help to save time and resources by acting as a support tool for planning and decision making (Mabhaudhi, Modi \& Beletse, 2013). Since extension services can transfer and implement research findings to local people, models and modelling, together with extension services, are at the core of kick starting aquaponics in countries like South Africa. As such, they could provide enough capacity to simplify aquaponics complexity for easy implementation to local people. This is important and necessary for countries such as South Africa (Statistics South Africa, 2014). The model could aid the layperson to optimally use the system for their benefit, and hence, achieve the related food security and/ or economic productivity (Rumbaugh, Jacobson \& Booch, 1999). Since aquaponics has only been shown to be an emerging practise, particularly in South Africa, it suggests that there is insufficient and perhaps incorrect data, information, resources and tools, if any, to help farmers to make the best decisions to better their opportunity to maximise their system productivity. Hence, this study seeks to develop a computer based model that is specific to South Africans conditions and environmental conditions.

\section{METHODOLOGY}

The study followed a mixed method approach which combined the methods and procedures of quantitative and qualitative data in a single study, using different sources of data. In this context, the study collected data from people who already have an aquaponics in place using a self-administered web-based questionnaire (online survey). Data from the model, observations, key informant face-to-face interviews and secondary literature relevant to the topic in discussion were also used. 
S. Afr. J. Agric. Ext.

Vol. 47 No. 1, 2019: 73 - 91

http://dx.doi.org/10.17159/2413-3221/2019/v47n1a491
Mchunu, Lagerwall \&

Senzanje

(License: CC BY 4.0)

\subsection{The model and its development}

A national (all nine provinces of South Africa) internet aquaponics survey was conducted with pre-coded questionnaire categories to be voluntarily administered to interested participants. Data were collected for a period of three months, from September to November 2016. A total of 44 aquaponics operators were captured from this study. The online survey results showed that there is a limited aquaponic systems population in South Africa, and that even those who are currently practising aquaponics in South Africa lack adequate management and production knowledge. Furthermore, it was determined that the development of the localised aquaponics model is important for South Africa for getting started with aquaponics. Hence, it was agreed upon that the model should be designed as simply as possible, at least for now, in order to kick start the optimisation of these systems. As such, the model was designed with one way irreversible pathways to ensure easy use of the model as it is a start-up version of the model (Figure 1). However, it was noted that while modelling and model development has great potential to provide a better opportunity to make better decisions to obtain maximum yields as aimed, its use and success is greatly dependant on the acceptability and user friendliness to the end user/ beneficiaries (Janse, 1997). Hence, model development principles guided the model development process. As guided by the principles of model development, it was decided to use the MS Excel platform because it incorporates advanced functions and is more available, accessible and user friendly to many local people in RSA compared to other platforms such as Java, C++, Matlab, Python, and Stella. Such a choice was logical to suggest, because if optimisation or kick starting of aquaponic systems in South Africa is to be achieved through this model, the model itself has to be user-friendly, available, easily accessible and applicable. To develop the model, data collected from the online survey and data (ratios) from literature (FAO, 2015; Rakocy, 1989; United State agency international development (USAID), 2013) were used to design, inform and calibrate model inputs. Furthermore, the Unified Modelling Language (UML) method and principles were employed in this study to design the model flow chart showing different aquaponics processes (Rumbaugh et al., 1999) as seen in Figure 1. The model was designed with the user interface as seen in Table 1. 


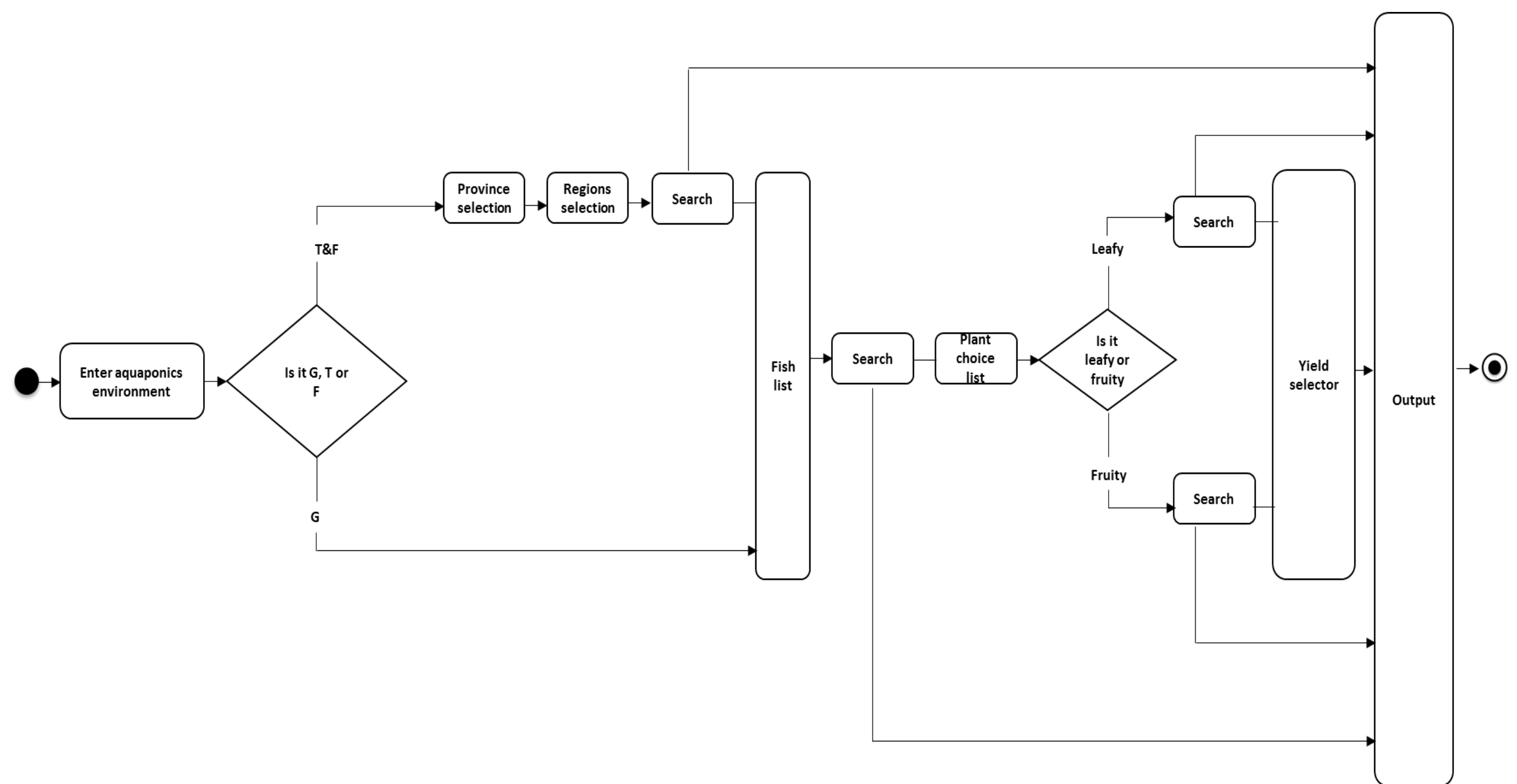

Figure 1: Aquaponic system model design processes flow chart ( $G$ stands for Greenhouse, $T$ stands for Tunnel and F stands for Field). 
S. Afr. J. Agric. Ext.

Vol. 47 No. 1, 2019: 73 - 91

http://dx.doi.org/10.17159/2413-3221/2019/v47n1a491
Mchunu, Lagerwall \&

Senzanje

(License: CC BY 4.0)

Table 1: Aquaponics model user interface.

\begin{tabular}{|c|c|}
\hline MODEL INPUT & INPUT COMMENTS \\
\hline Aquaponics environment selector & $\begin{array}{l}\text { What type of environment would you like your aquaponics to } \\
\text { be at or is at? }\end{array}$ \\
\hline Locality selector & Where is your aquaponics located by province? \\
\hline Region selector & Where is your aquaponics located by region? \\
\hline Fish type selector & $\begin{array}{l}\text { What type of fish species you would like to grow in your } \\
\text { aquaponics? }\end{array}$ \\
\hline Crop type selector & What is your aquaponics crop choice? \\
\hline Yield selector $(\mathrm{kg})$ & What is your desired crop yield per week? \\
\hline OUTPUT & OUTPUT COMMENTS \\
\hline Required plant population (kg) & $\begin{array}{l}\text { Total plants required in the system in order to harvest every } \\
\text { week. }\end{array}$ \\
\hline Required plant growing area $\left(\mathrm{m}^{2}\right)$ & $\begin{array}{l}\text { Total planting surface area required to support plant density } \\
\text { (FAO, 2015; Lennard, 2012; Rakocy 1989). }\end{array}$ \\
\hline $\begin{array}{l}\text { Required daily fish feed rate }(\mathrm{g} / \\
\left.\text { day }^{-1}\right)\end{array}$ & $\begin{array}{l}\text { Suggested daily fish feed amount based on FAO (2015) and } \\
\text { Rakocy (1989) ratios. }\end{array}$ \\
\hline $\begin{array}{l}\text { Required fish stocking density } \\
\left(\mathrm{kg} / \mathrm{m}^{3}\right)\end{array}$ & Suggested fish stocking density based on FAO $(2014 ; 2015)$. \\
\hline Suggested fish tank size $(\mathrm{L})$ & $\begin{array}{l}\text { Suggested fish tank size based on FAO }(2014 ; 2015) \text { and } \\
\text { Rakocy (1989). }\end{array}$ \\
\hline Required biofilter area $\left(\mathrm{m}^{2}\right)$ & $\begin{array}{l}\text { Surface area required to mineralise fish waste solids based on } \\
\text { FAO (2015) ratios. }\end{array}$ \\
\hline Required flow rate (L/hr) & $\begin{array}{l}\text { Water required to flow to your plant growing area based on } \\
\text { FAO (2015), Lennard (2012) and Rakocy (1989). }\end{array}$ \\
\hline $\begin{array}{l}\text { Recommended method of plant } \\
\text { production }\end{array}$ & $\begin{array}{l}\text { A recommended plant production method based on FAO } \\
\text { (2015), Lennard (2012) and Rakocy (1989). }\end{array}$ \\
\hline $\begin{array}{l}\text { Needed fish temperature } \\
\text { adjustments }\left({ }^{\circ} \mathrm{C}\right)\end{array}$ & $\begin{array}{l}\text { A recommended temperature adjustment to meet fish } \\
\text { optimum temperature in RSA. }\end{array}$ \\
\hline $\begin{array}{l}\text { Nutrient management, } \mathrm{K}, \mathrm{Ca} \text { and } \\
\mathrm{Fe}(\mathrm{mg} / \mathrm{L})\end{array}$ & $\begin{array}{l}\text { Levels of limiting nutrients to be achieved for optimum plant } \\
\text { yield based on Lund (2014). }\end{array}$ \\
\hline $\begin{array}{l}\text { Required winter fish temp } \\
\text { adjustments if it Tunnel }\left({ }^{\circ} \mathrm{C}\right)\end{array}$ & $\begin{array}{l}\text { A recommended winter temperature adjustment to meet fish } \\
\text { optimum temperature if tunnel housing is used. }\end{array}$ \\
\hline $\begin{array}{l}\text { Required summer fish temp } \\
\text { adjustments if it Tunnel }\left({ }^{\circ} \mathrm{C}\right)\end{array}$ & $\begin{array}{l}\text { A recommended summer temperature adjustment to meet fish } \\
\text { optimum temperature if tunnel housing is used. }\end{array}$ \\
\hline
\end{tabular}

\subsection{Model calibration}

A plant list generated from the 44 aquaponics operators was categorised as leafy and fruity as per the reviewed literature $(\mathrm{FAO}, 2014)$ and were assigned to specific production ratios as per plant type (fruity or leafy vegetable) (Table 2). The aquaponics production ratios put forward by FAO (2014) and Rakocy (1989) were used to develop an aquaponics model. The model predicts specifications for aquaponics production unit based on a desired yield input function by a user from a model dropdown list. The yield selector input was designed as the main model input to generate model outputs. The main aquaponics model output variables include fish 
S. Afr. J. Agric. Ext.

Vol. 47 No. 1, 2019: 73 - 91

http://dx.doi.org/10.17159/2413-3221/2019/v47n1a491
Mchunu, Lagerwall \&

Senzanje

(License: CC BY 4.0)

stocking density, daily fish feed, and required planting area (FAO, 2014). To calibrate different plant types to match with aquaponics production ratios in order for the model to predict the required fish stocking density, daily fish feed and required planting area, it was assumed that the average market size of any individual plant type is $500 \mathrm{~g}$ including those that work in bunches such as spinach, basil, and salad greens. Thus, 25 heads of lettuce translated to 12.5 $\mathrm{kg} / \mathrm{m}^{2}$, in calculation: $(25 \times 0.5 \mathrm{~kg}$ or $25 \times 500 \mathrm{~g} / 1000 \mathrm{~g}=12.5 \mathrm{~kg})$. See Table 2 and Figure 2 for clear ratios and calculations on how planting area, daily fish feed and fish stocking density were determined. A similar method was applied to fruity vegetables giving $4 \mathrm{~kg} / \mathrm{m}^{2}$, in calculation: $(8 \times 0.5 \mathrm{~kg}$ or $8 \times 500 \mathrm{~g} / 1000 \mathrm{~g}=4 \mathrm{~kg})$. The model was designed to predict yield output for the cycle of weekly harvest thereby determining how much plant population will be needed to be in the system. To determine how much a farmer will be able to harvest per week, crop growth duration was multiplied by desired yield input. For example, lettuce takes four weeks to grow and if a farmer wishes to harvest 25 heads of lettuce every week, $4 \times 25=100$ heads will be needed to be in the system in order to harvest weekly. Fish tank volume size was based on the FAO (2015) ratios that showed that $10 \mathrm{~kg} / \mathrm{m}^{3}$ fish stocking must be stocked in $1000 \mathrm{~m}^{3}$ for optimal nutrient turn over, and all provinces' and regional temperature was obtained from the 2016 South African Weather Service.

Table 2: Derived aquaponics production ratios.

\begin{tabular}{|c|c|c|}
\hline Vegetable category & Fish feed per day & Planting density \\
\hline Leafy vegetables & $\begin{array}{c}40-50(\mathrm{FAO}, 2014 ; \mathrm{FAO}, 2015) \text { or 50-60 } \\
\text { (Rakocy, 1989). }\end{array}$ & $\begin{array}{c}20-25 \text { (Rakocy, 1989; FAO, } \\
2014) .\end{array}$ \\
\hline Fruity vegetables & $80-100$ (Rakocy, 1989; FAO, 2014). & $\begin{array}{c}4-8 \text { (Rakocy, 1989; FAO, 2014; } \\
\text { FAO 2015). }\end{array}$ \\
\hline
\end{tabular}


S. Afr. J. Agric. Ext.

Vol. 47 No. 1, 2019: 73 - 91

http://dx.doi.org/10.17159/2413-3221/2019/v47n1a491
Mchunu, Lagerwall \&

Senzanje

(License: CC BY 4.0)

Lettuce requires 4 weeks to grow once the seedlings are transplanted into the system, and 25 heads per week are harvested, therefore:

25 heads $/$ week $\times 4$ weeks $=100$ heads in system

Each 25 heads of lettuce require $1 \mathrm{~m}^{2}$ of growing space, therefore:

$$
100 \text { heads } \times \frac{1 \mathrm{~m}^{2}}{25 \text { heads }}=4 \mathrm{~m}^{2}
$$

Each square metre of growing space requires $50 \mathrm{~g}$ of fish feed per day, therefore:

$$
4 \mathrm{~m}^{2} \times \frac{50 \mathrm{grams} \text { feed } / \text { day }}{1 \mathrm{~m}^{2}}=200 \mathrm{grams} \text { feed } / \text { day }
$$

Required fish

feed in order to

generate

The fish (biomass) in a system eats 1-2 percent of their body weight per day, therefore:

200 grams feed $/$ day $\times \frac{100 \text { grams fish }}{1-2 \text { grams feed } / \text { day }}=10-20 \mathrm{~kg}$ of fish biomass

Figure 2: Calculation that led to model calibration as it relates to required plant population, planting area, daily fish feed and fish stocking density (FAO, 2015).

\subsection{Biofilter area}

Biofilter area is a very important part of an aquaponic system because it determines the microbial component functioning, which in turn determines the productivity of the aquaponic system by facilitating nutrient turn over and flow in the aquaponic systems. Hence, biofilter area was determined using FAO (2014) ratios from Equations 1 and 2.

$$
(\mathrm{g} / \text { feed }) \times 0.32 \times 0.16 \times 0.61 \times 1.2=\mathrm{g} / \text { ammonia }
$$

Where,

$0.32=\mathrm{g}$ protein is $32 \%$ protein in $(\mathrm{g} / \mathrm{feed})$,

$0.16=\mathrm{g}$ of nitrogen contained in the protein,

$0.61=\mathrm{g}$ of wasted nitrogen, and

1.2 = each gram of wasted nitrogen, $1.2 \mathrm{~g}$ of ammonia is produced.

$$
\frac{1 \mathrm{~m}^{2}}{0,57 \mathrm{~g} \text { ammonia }}
$$

Where,

$0.57=\mathrm{g}$ ammonia removal rate by bacteria per day $/ \mathrm{m}^{2}$ 
S. Afr. J. Agric. Ext.

Vol. 47 No. 1, 2019: 73 - 91

http://dx.doi.org/10.17159/2413-3221/2019/v47n1a491
Mchunu, Lagerwall \&

Senzanje

(License: CC BY 4.0)

\subsection{Water flowrate}

Water flowrate was determined following a ratio that suggests that $30-40 \%$ of water circulation of total fish tank water should be channelled to the plant growing area (FAO, 2014).

\subsection{Recommended method of plant production}

The method of plant production was based on FAO (2015), Lennard (2012) and Rakocy (1989). The Lennard recommendation comes from more than five years of aquaponics research and Rakocy ratios come from more than 25 years of aquaponic systems research.

\subsection{Recommended temperature adjustments}

It is well documented that the independent economic cultivation of fresh water fish is nearly impossible to practice in South Africa. Therefore, to determine the model summer and winter temperature adjustments, the regional winter and summer average temperatures were subtracted from fish optimum temperatures, thereby resulting in the system environmental conditions being at optimum levels at all times. This was done for the field condition option, however, if option is tunnel, a $5^{\circ} \mathrm{C}$ was further added to the recommended temperature adjustment. The reason for this is because, according to the literature, if tunnel environment is constructed well, it could raise air temperature with an average of $5^{\circ} \mathrm{C}$. For the greenhouse option, it was assumed that in the greenhouse environment all production parameters can be fully controlled, hence, outside environmental conditions are not factors needing to be considered.

\subsection{Validation and verification}

A validation process was performed by manually matching and calculating all model inputs and outputs databases using aquaponic production ratios as was put forward by FAO (2015), Lennard, (2012) and Rakocy, (1989). In terms of verification, aquaponic production data collected from local farmers all over the country was used. The online survey data was organised and summarised to create main model input, which was the yield selector. This was performed by taking all of the crop yield results from the online survey data and transforming it until it matched the units of the yield selector of the model. This was determined by taking crop yield results from the online data, which was based on yearly average yield $(\mathrm{kg})$. Thereafter, this was divided by individual crop duration and rotation cycle. This was conducted in order to determine how much produce $(\mathrm{kg})$ the farmers produced per individual crop rotation.

\subsection{Simulations}

To carry out simulations, crop production data of each farmer from the survey was used to generate model output units. The observed fish stocking density, daily fish feed and planting area data from the online survey were compared with simulated data from the model. This determined the effectiveness of the model to predict main aquaponic systems components for start-up. 
S. Afr. J. Agric. Ext.

Vol. 47 No. 1, 2019: 73 - 91

http://dx.doi.org/10.17159/2413-3221/2019/v47n1a491
Mchunu, Lagerwall \&

Senzanje

(License: CC BY 4.0)

\subsection{Analysis}

Data analysis was carried out using the General Linear Model. Repeated measures using the Genstat 18th Statistical Package was used to compare variable means. Statistical significance was determined at the 5\% probability level. Furthermore, the analysis was done using goodness of fit of simulated model outputs against observed field measurements by using the coefficient of determination $\left(\mathrm{R}^{2}\right)$.

\section{RESULTS}

The main variables that were measured to derive most findings were fish stocking density $\left(\mathrm{kg} / \mathrm{m}^{3}\right)$, daily fish feed $(\mathrm{g})$, and planting area $\left(\mathrm{m}^{2}\right)$.

\subsection{Model explanation and operation}

The green highlighted columns in Figures 3, 4 and 5 are all inputs section of the model and all light blue highlighted columns are the required and suggested outputs or outcomes of the model. All inputs sections were designed as a dropdown list. The model starts with the selection of the aquaponics environment currently at or planned to be at. This section consists of three options, namely field, tunnel and greenhouse. When a farmer selects tunnel or field, the model will allow a farmer to select the locality by province, which includes specifying different regions within the selected province, giving an output of how much the temperature needs to be adjusted to in winter and in summer (Figure 3). This is because it is well documented that RSA average yearly temperatures do not support independent viable fish production population. When tunnel is selected, an addition of $5^{\circ} \mathrm{C}$ is added to temperature adjustments both for winter and summer. This is because when tunnel environment is constructed well, it has the capacity of raising the inside temperatures with an average of $5^{\circ} \mathrm{C}$ (Figure 4), but when greenhouse is selected the model does not make locality process available (Figure 5). This is because it was assumed that in greenhouse conditions, all environmental conditions (wind speed, relative humidity and air temperature) could be fully controlled, including solar radiation. Those assumptions do not hold true in both tunnel and field conditions. When different plants are selected from the dropdown list, the model searches and matches its production ratios and provides outputs based on the selected plant category. Head lettuce represents all leafy vegetables and tomatoes represent all fruity vegetables (Figure 3 and 4 respectively). The main model input is the yield selector. In this section, a farmer/ grower decides how much yield he/ she wants to harvest per week. However, it was also acknowledged and welcomed that some hobby scale may not be interested in yield harvest, however, in the interest of kick-starting, promoting and optimising aquaponics in RSA, all model inputs were designed to generate some harvestable yield. 
S. Afr. J. Agric. Ext.

Vol. 47 No. 1, 2019: 73 - 91

http://dx.doi.org/10.17159/2413-3221/2019/v47n1a491
Mchunu, Lagerwall \&

Senzanje

(License: CC BY 4.0)

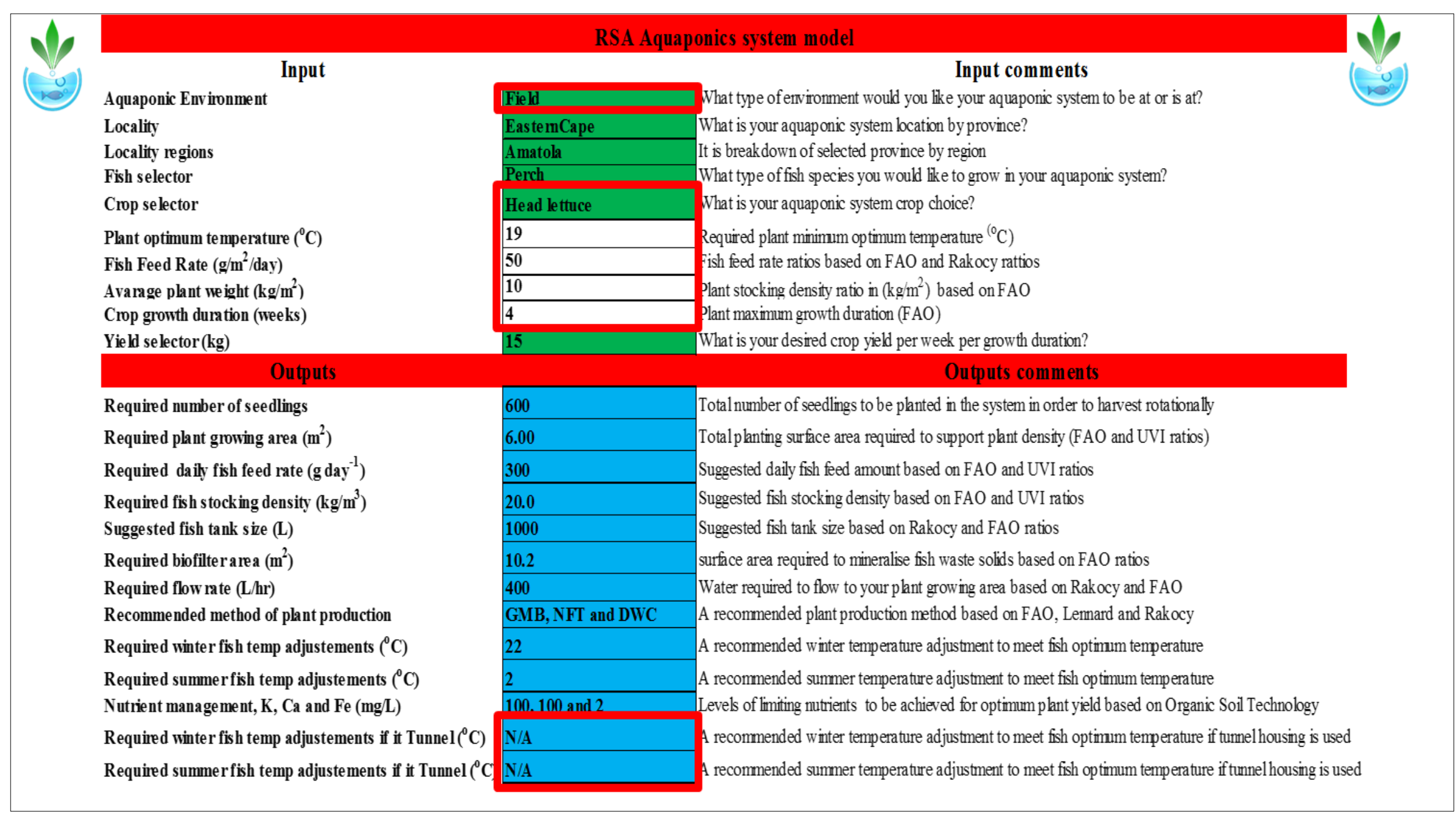

Figure 3: RSA aquaponic system model as it relates to the effect of field aquaponics environment. 
S. Afr. J. Agric. Ext.

Vol. 47 No. 1, 2019: 73 - 91

http://dx.doi.org/10.17159/2413-3221/2019/v47n1a491
Mchunu, Lagerwall \&

Senzanje

(License: CC BY 4.0)

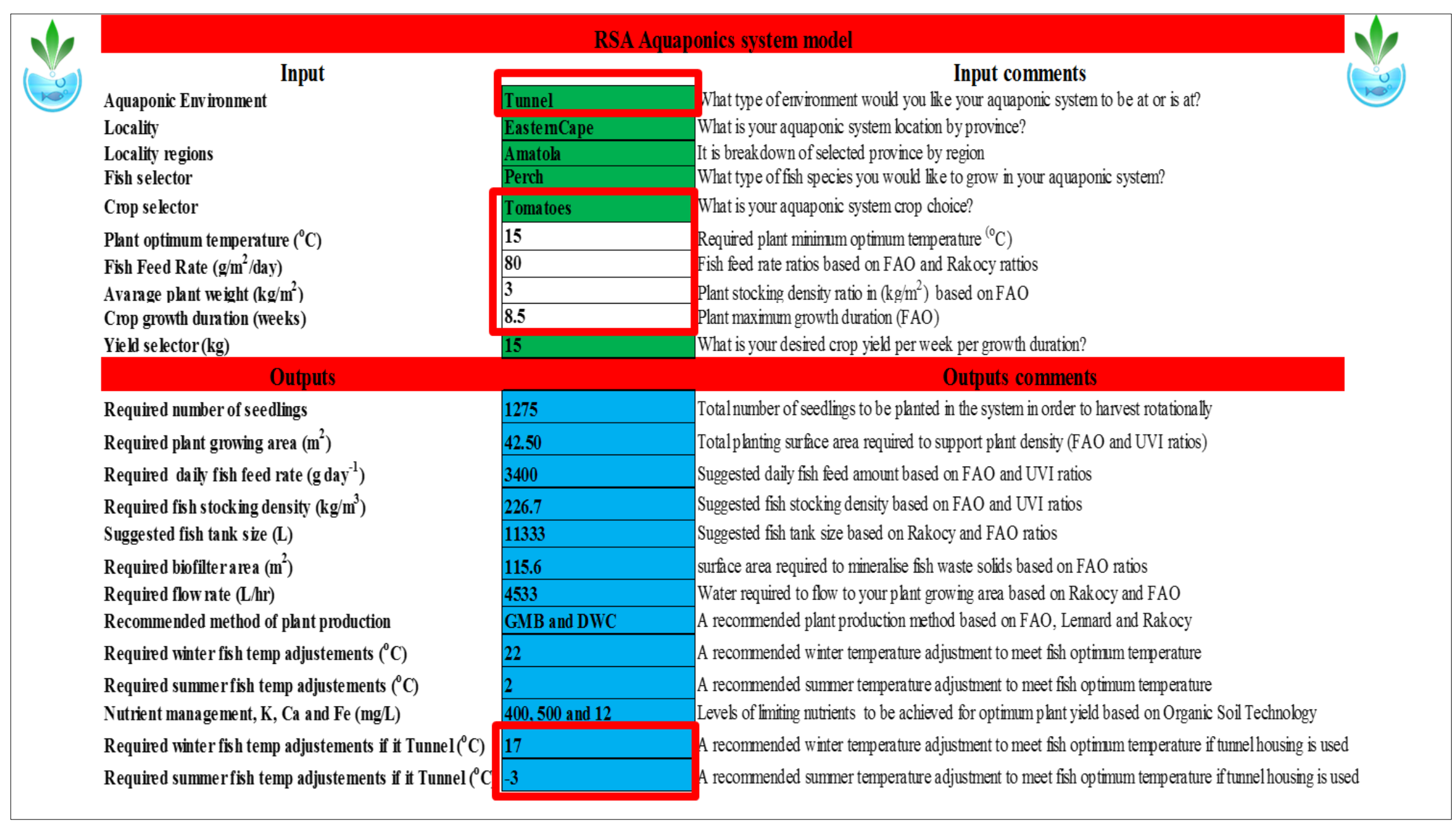

Figure 4: RSA aquaponics model as it relates to the effect of tunnel aquaponics environment. 
S. Afr. J. Agric. Ext.

Vol. 47 No. 1, 2019: 73 - 91

http://dx.doi.org/10.17159/2413-3221/2019/v47n1a491
Mchunu, Lagerwall \&

Senzanje

(License: CC BY 4.0)

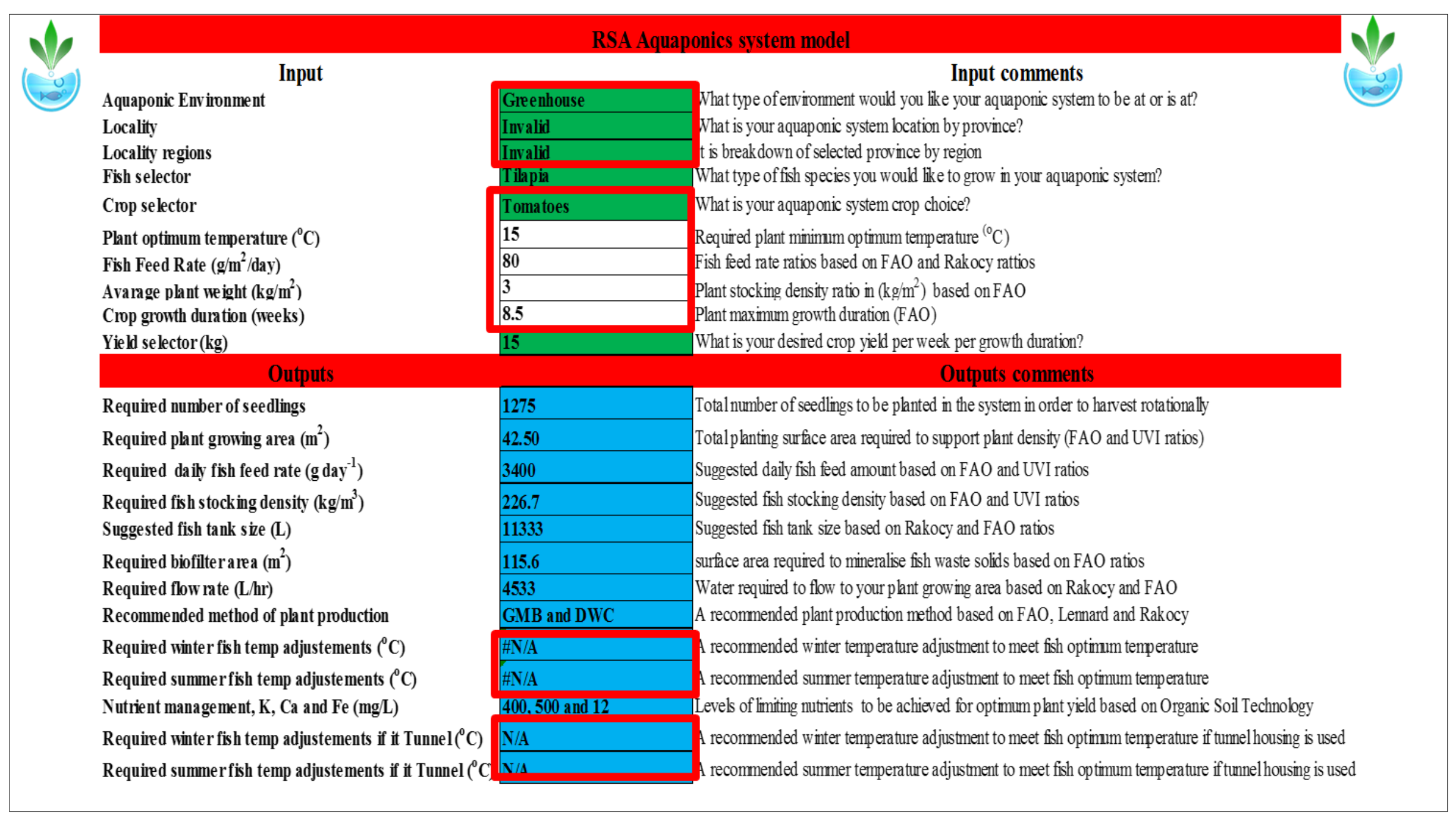

Figure 5: RSA aquaponics model as it relates to the effect of greenhouse aquaponics environment. 
S. Afr. J. Agric. Ext.

Vol. 47 No. 1, 2019: 78 - 96

http://dx.doi.org/10.17159/2413-3221/2019/v47n1a491
Mchunu, Lagerwall \&

Senzanje

(License: CC BY 4.0)

\subsection{Simulation output}

After the online survey data was filtered and transformed, most aquaponics farmers crop production yield output fitted under yield selector of 1 and $2 \mathrm{~kg} / \mathrm{week} / \mathrm{harvest}$ duration (90\%) of the model input function. This is the lowest model output input. There were no significant differences $(\mathrm{P}<0.05)$ between the observed and simulated output within fish stocking density, fish feed and planting area variables respectively (Figures 6, 7 and 8). See Tables 3, 4 and 5 for specific $\mathrm{P}$ values of different variables. The mean for fish stocking density, daily fish feed and planting area between observed and simulated output was 30-34, 548-518, and 7-6 respectively. The fit for fish stocking density and fish feed rate was $R=0.7477$ and 0.6957 respectively and the fit was $R=0.4313$ for plant growth area (Figures 9, 10 and 11).

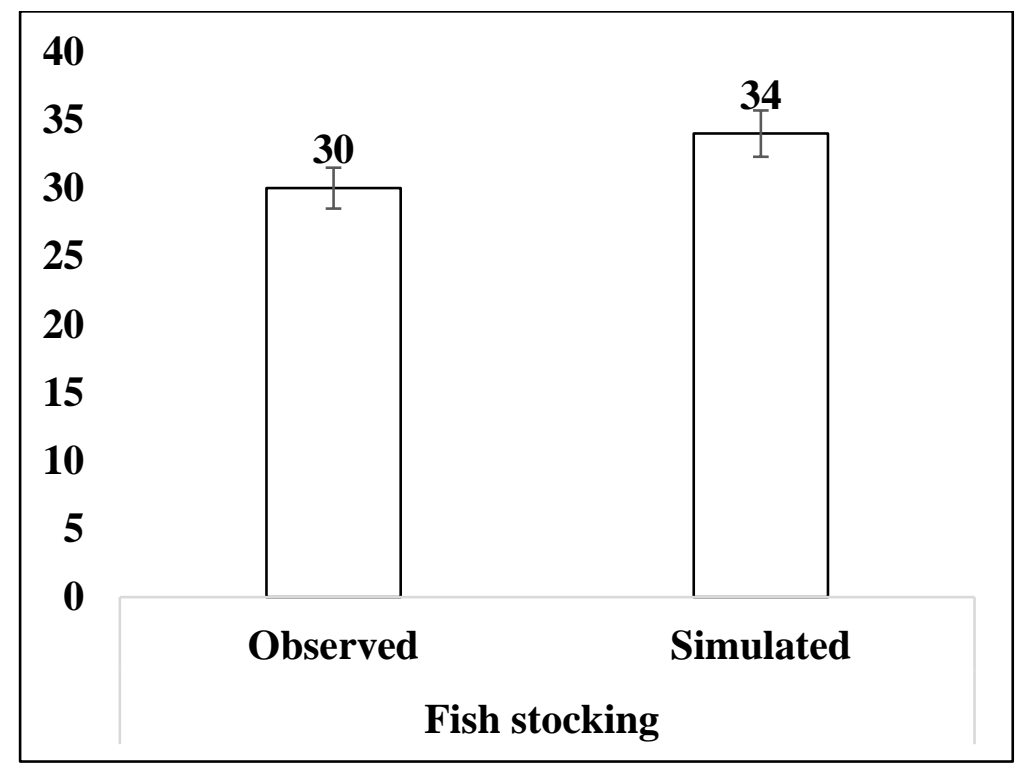

Figure 6: Aquaponics fish stocking density as it relates to observed and simulated data from the RSA model.

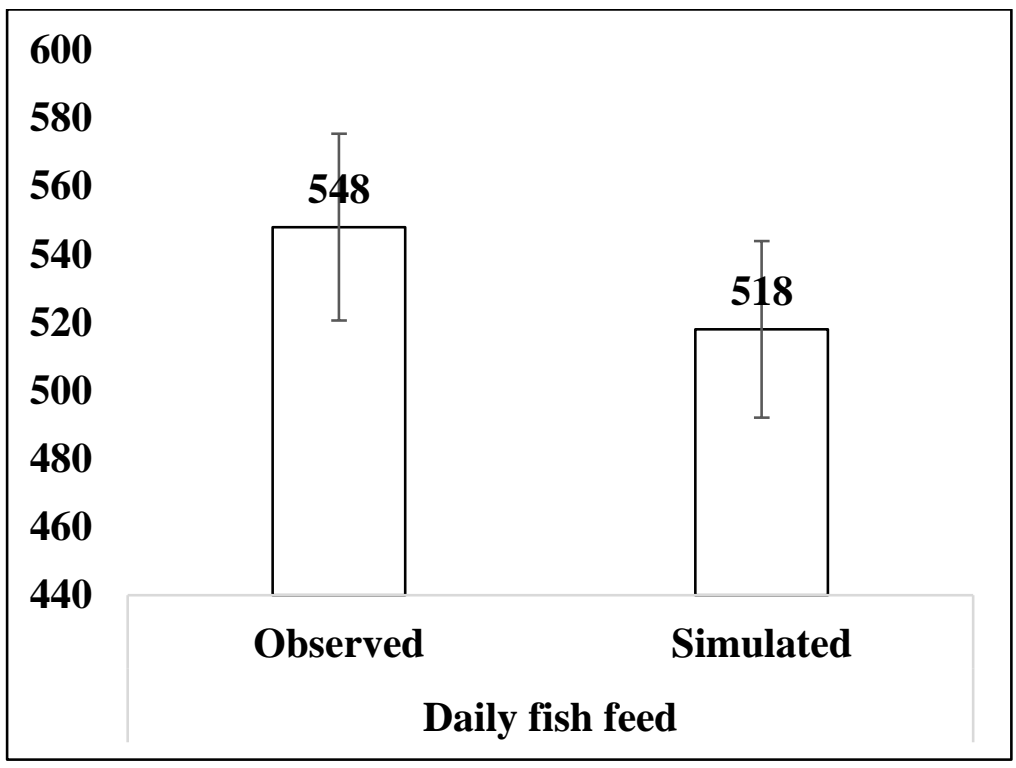


S. Afr. J. Agric. Ext.

Vol. 47 No. 1, 2019: 73 - 91

http://dx.doi.org/10.17159/2413-3221/2019/v47n1a491
Mchunu, Lagerwall \&

Senzanje

(License: CC BY 4.0)

Figure 7: Aquaponics daily fish feed as it relates to observed and simulated data from the RSA model.

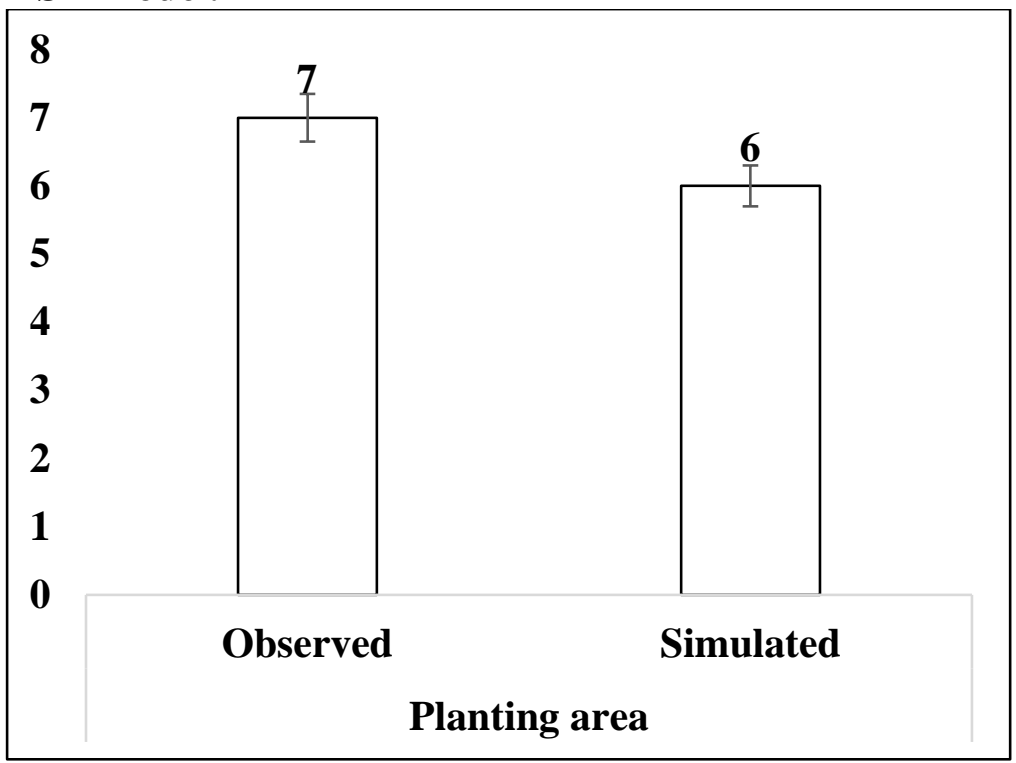

Figure 8: Aquaponics planting area as it relates to observed and simulated data from the RSA model.

Table 3: ANOVA table for fish stocking density.

\begin{tabular}{|l|l|l|l|l|l|}
\hline & df & SS & MS & F & P value \\
\hline Regression & 1 & 10180.47 & 10180.47 & 120.1252914 & $9.30022 \mathrm{E}^{-14}$ \\
\hline Residual & 43 & 3474.698 & 84.74872 & & \\
\hline Total & 44 & 13655.16 & & & \\
\hline
\end{tabular}

Table 4: ANOVA table for fish feed.

\begin{tabular}{|l|l|l|l|l|l|}
\hline & df & SS & MS & F & P value \\
\hline Regression & 1 & 3275310 & 3275310 & 93.95076 & $3.64 \mathrm{E}^{-12}$ \\
\hline Residual & 43 & 1429341 & 34861.98 & & \\
\hline Total & 44 & 4704651 & & & \\
\hline
\end{tabular}

Table 5: ANOVA table for planting area.

\begin{tabular}{|l|l|l|l|l|l|}
\hline & df & SS & MS & F & P value \\
\hline Regression & 1 & 406.012 & 406.012 & 32.27013 & $1.23025 \mathrm{E}^{-06}$ \\
\hline Residual & 43 & 515.8484 & 12.58167 & & \\
\hline Total & 44 & 921.8605 & & & \\
\hline
\end{tabular}


S. Afr. J. Agric. Ext.

Vol. 47 No. 1, 2019: 73 - 91

http://dx.doi.org/10.17159/2413-3221/2019/v47n1a491
Mchunu, Lagerwall \&

Senzanje

(License: CC BY 4.0)

\section{Fish stocking}

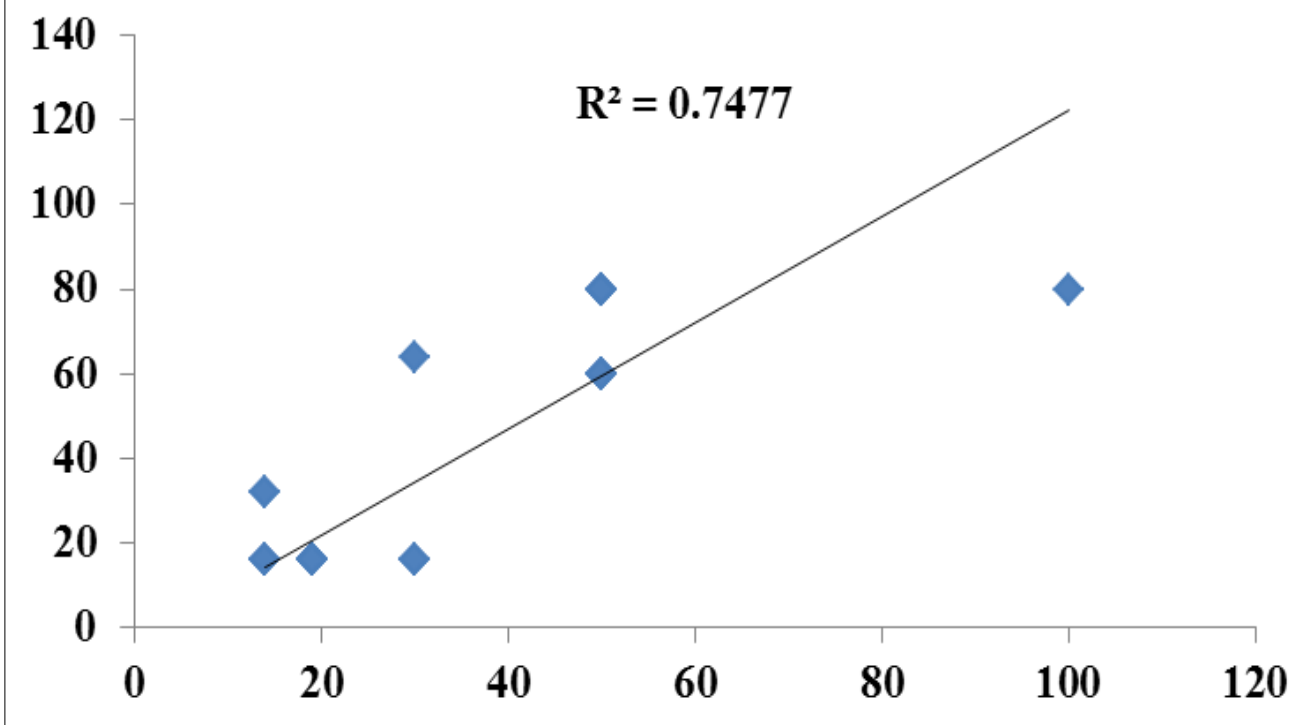

Figure 9: Verification result of the developed RSA aquaponics model as it relates to aquaponics fish stocking density.

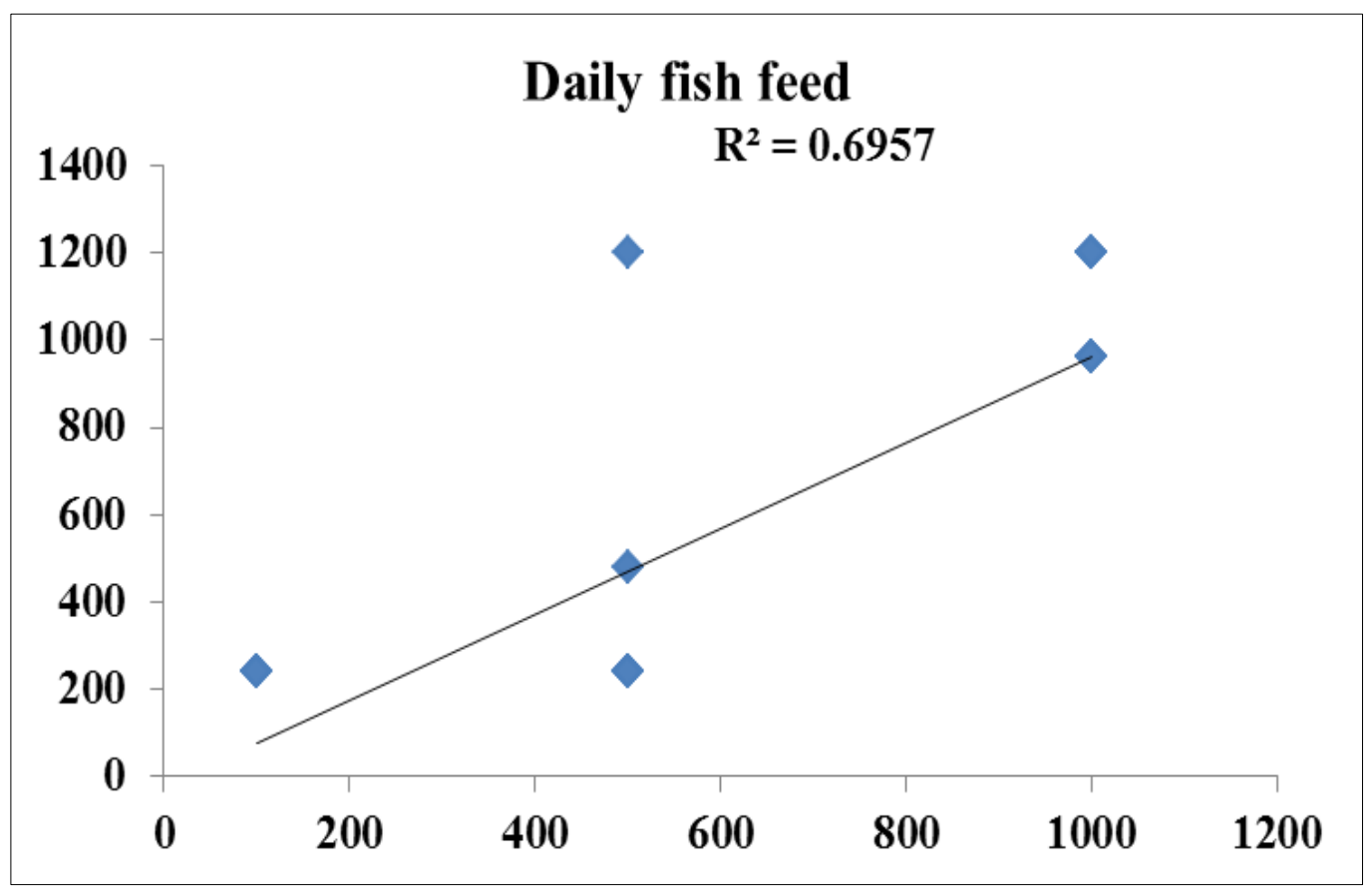

Figure 10: Verification result of the developed RSA aquaponics model as it relates to aquaponics daily fish feed. 


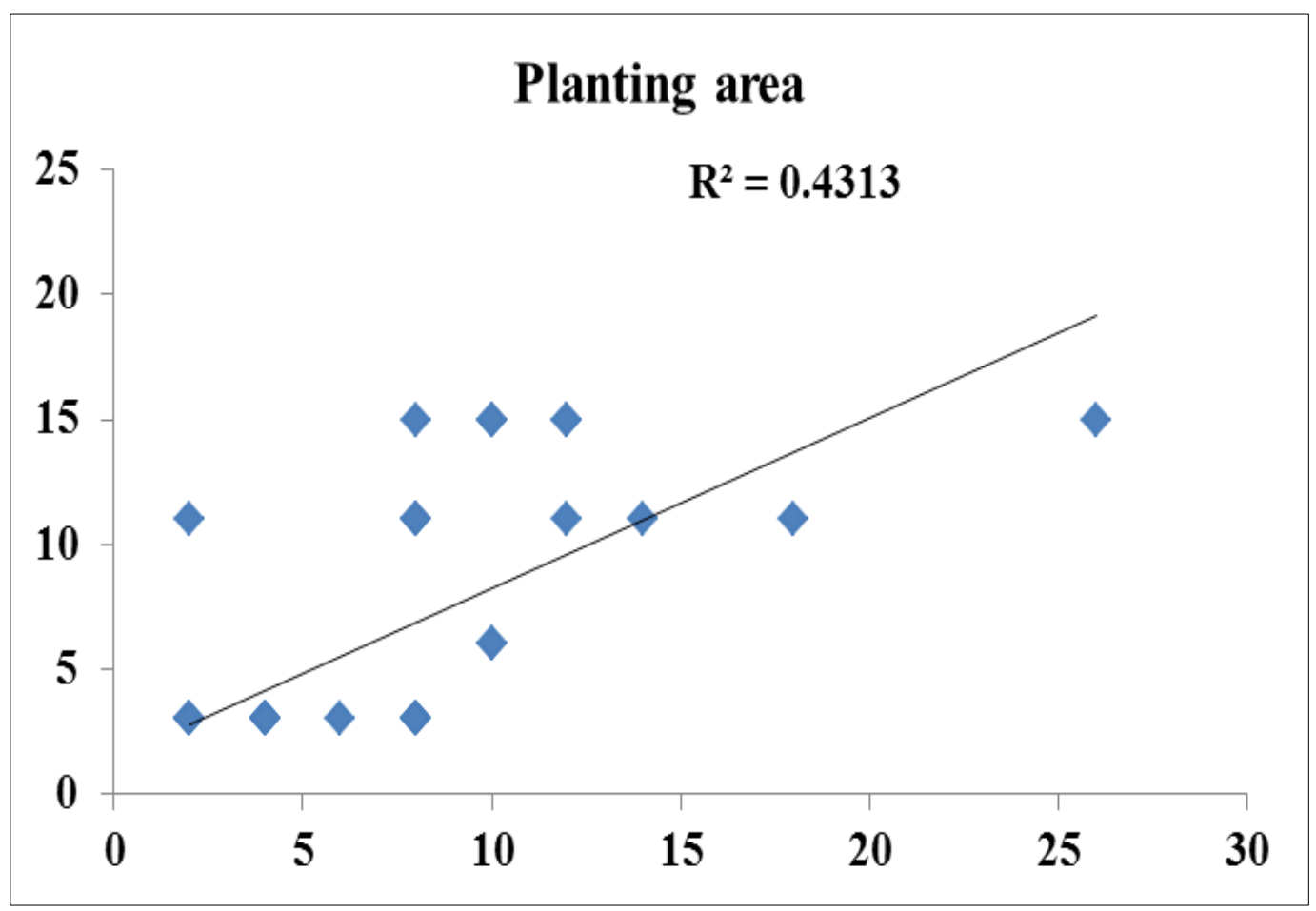

Figure 11: Verification result of the developed RSA aquaponics model as it relates to aquaponics planting area.

\section{DISCUSSION}

The higher percentage (90\%) fit of aquaponics farmers yield output to the lowest model out of 1 and $2 \mathrm{~kg} /$ week/harvest model input suggests that most local aquaponics are characterised by small systems. Alternatively, it could be that most local aquaponics farmers produce below optimum capacity. This could be explained by the findings of Mchunu, Lagerwall and Senzanje (2017) who suggested that there is little information, data, resources and tools available, if any, to help local aquaponics farmers to have a better opportunity to obtain maximum yield in their systems. This is also supported by Love and colleagues' (2015) international aquaponics survey findings which showed and suggested that aquaponics is an emerging practice worldwide. There was only one response captured for South Africa from this study, which particularly suggests that aquaponics is a new and emerging practice in South Africa (Love et al., 2014).

Agricultural extension is the delivery of information to farmers, particularly small-scale farmers (FAO, 2015). Extension supports have been shown to be effective in implementing successful community projects in South Africa (Faber, Witten \& Drimie, 2011). Agricultural extension can simplify complex scientific information into simple practical forms for famers. Thus, there is a need to employ extension support services if these systems were to be implemented for the first time in South Africa. This is because it has been shown that most local people that are affected by poverty make up the majority of South Africa's human population, resides in rural areas and have significantly low literacy levels, particularly smallscale farmers (Statistics South Africa, 2014).

The similarities between the observed and simulated data within fish stocking density, fish feed, and planting area, along with the model good fit for fish stocking density and fish feed 
S. Afr. J. Agric. Ext.

Vol. 47 No. 1, 2019: 73 - 91

http://dx.doi.org/10.17159/2413-3221/2019/v47n1a491
Mchunu, Lagerwall \&

Senzanje

(License: CC BY 4.0)

rate, of $R=0.7559$ and 0.6957 , suggests that this model can be trusted and used to predict these parameters. This is explained by the coefficient of determination $\left(R^{2}\right)$. The coefficient of determination $\left(R^{2}\right)$ is a statistical measurement of how close the data are to the fitted regression line in the graph and is used when comparing the observed and predicted model output values. The $R^{2}$ always falls between 0 and $100 \%$, where $0 \%$ shows that the model explains none of the variability of the response data around its mean, and $100 \%$ indicates that the model explains all the variability of the response data around its mean. Hence, the higher or closer the $R^{2}$ is to 1 , the better the model fits the measured data. The $R=0.4279$ for planting density suggests a poor model fit. This could also be attributed to growers producing at a negative level, because of the lack of information and availability of tools such as an RSA aquaponics model.

\section{GUIDELINES FOR EXTENSION OFFICERS AND EXTENSION SUPPORT AGENCIES}

To use the model effectively in RSA, extension officers or extension services need to have or understand the following:

- Aquaculture background to understand fish tank requirements to keep fish safe and healthy by ensuring that fish convert all fish feed into needed waste by plants in hydroponic culture.

- Microbiology background to ensure that conditions required for transformation of ammonium nitrogen into nitrate nitrogen are provided for nutrient rich waste produced in the fish tank to be available for plant uptake. This is because waste produced from the water tank is in ammonium form and needs to be transformed into nitrate for plants to take it up in the hydroponic culture. This is a very important component of an aquaponic system because it determines nutrient turn over and nutrients available for plant and water quality for fish in the fish tank. In the absence of this component, the whole system will collapse.

- Hydroponic background to understand plant nutrient requirements and different aquaponics plant categories, because this model is very sensitive to plant categories. Leafy vegetables have a significantly different nutrient requirement and planting density than fruity vegetables. One mistake could lead to a significant outcome thus affecting budget and resource efficiency. Thus, an extension officer should be able to quickly notice if something is wrong before model output is taken into consideration.

- Meteorology background to be able to provide better advice to farmers, particularly small-scale farmers, about what type of aquaponic system to use (tunnel, field and greenhouse environment or hobby, subsistence or commercial scale), which is suitable for what type of fish and plant species, and in what type of area. This is because it is well documented that South African environmental conditions are not suitable for independent economic fish production.

- Modelling background to be able to use the model to calibrate, verify and validate the model according to different farmers' scenarios.

\section{CONCLUSION}

The developed model is able to predict the main aquaponic system inputs, namely fish stocking density, daily fish feed, and required planting area. The effectiveness of this model to increase food produced with or in aquaponics could be facilitated by extension support service agencies. 
S. Afr. J. Agric. Ext.

Vol. 47 No. 1, 2019: 73 - 91

http://dx.doi.org/10.17159/2413-3221/2019/v47n1a491
Mchunu, Lagerwall \&

Senzanje

(License: CC BY 4.0)

The suitability of the model to be adopted by extension agencies is increased or is made effective by model extension guidelines.

\section{REFERENCES}

FABER, M., WITTEN, C. \& DRIMIE, S., 2011. Community-based agricultural interventions in the context of food and nutrition security in South Africa. South Afri. J. Clin. Nutr., 24(1):21-30.

FOOD AND AGRICULTURAL ORGANISATION (FAO), 2014. Small-scale aquaponic food production. FAO fisheries and aquaculture technical paper, Rome, Italy.

FOOD AND AGRICULTURAL ORGANISATION (FAO), 2015. Land and property rights: Junior farmer field and life school, facilitator's guide. Aquaculture, ISBN 978-92-5108143-3, Rome, Italy.

GODDEK, S., DELAIDE, B., MANKASINGH, U., RAGNARSDOTTIR, K.V., JIJAKLI, H. \& THORARINSDOTTIR, R., 2015. Challenges of sustainable and commercial aquaponics. Sustainability, 7(4):4199-4224.

IBIRONKE, O.A., 2013. Glasshouse production of vegetables and ornamentals for agricultural productivity in Nigeria. World J. Agric. Sci., 1:113-119.

JANSE, J.H. 1997. A model of nutrient dynamics in shallow lakes in relation to multiple stable states. Hydrobiologia. 342:1-8.

LENNARD, W., 2012. Aquaponic system design parameters.: Fish to plant rations (feeding rate ratios). Aquaponics Solutions, 3:10.

LOVE, D.C., FRY, J.P., GENELLO, L., HILL, E.S., FREDERICK, J.A., LI, X. \& SEMMENS, K., 2014. An international survey of aquaponics practitioners. PLoS One., 9(7):102662.

LOVE, D.C., FRY, J.P., LI, X., HILL, E.S., GENELLO, L., SEMMENS, K. \& THOMPSON, R.E., 2015. Commercial aquaponics production and profitability: Findings from an international survey. Aquac., 435:67-74.

LUND, J. 2014. Aquaculture effluents as fertilizer in hydroponic cultivation: A case study comparing nutritional and microbiological properties. Swedish University of Agricultural Sciences, 1-19.

MABHAUDHI, T., MODI, A.T. \& BELETSE, Y.G., 2013. Response of taro (Colocasia esculenta L. Schott) landraces to varying water regimes under a rainshelter. Agric. Water Manag., 121:102-112.

MCHUNU, N., LAGERWALL, G. \& SENZANJE, A., 2017. Food sovereignty for food security, aquaponics as a potential method: A review. J. Aquac. Res. Dev., 8:1-9. 
S. Afr. J. Agric. Ext.

Vol. 47 No. 1, 2019: 73 - 91

http://dx.doi.org/10.17159/2413-3221/2019/v47n1a491
Mchunu, Lagerwall \&

Senzanje

(License: CC BY 4.0)

MCHUNU, N., ODINDO, A. \& MUCHAONYERWA, P., 2018. The effects of urine and urine-separated plant nutrient sources on growth and dry matter production of perennial ryegrass (Lolium perenne. L). Agric. Water Manag., 207:37-43.

MINISTRY OF AGRICULTURE FOOD SECURITY AND COOPERATIVES, 2006. Follow-up of the implementation of the World Food Summit Plan of Action. Security. $1-16$.

RAKOCY, I.E., 1989. Tank culture of tilapia. SRAC Publ., 17:523-529.

RUMBAUGH, J., JACOBSON, I. \& BOOCH, G., 1999. The UML reference manual. New York: Addison-Wesley.

STATISTICS SOUTH AFRICA, 2014. Poverty trends in South Africa: An examination of absolute poverty between 2006 and 2011, Statistics South Africa.

SWAP, R.J., ANNEGARN, H.J., SUTTLES, J.T., HAYWOOD, J., HELMLINGER, M.C., HELY, C., HOBBS, P.V., HOLBEN, B.N., JI, J., KING, M.D., LANDMANN, T., MAENHAUT, W., OTTER, L., PAK, B., PIKETH, S.J., PLATNICK, S., PRIVETTE, J., ROY, D., THOMPSON, A.M., WARD, D. \& YOKELSON, R., 2002. The Southern African Regional Science Initiative (SAFARI 2000): Overview of the dry season field campaign. S. Afr. J. Sci., 98:125-130.

TURCIOS, A.E. \& PAPENBROCK, J., 2014. Sustainable treatment of aquaculture effluentswhat can we learn from the past for the future? Sustainability, 6(2):836-856.

UNITED STATE AGENCY INTERNATIONAL DDEVELOPMENT, 2013. Sustainable fisheries and responsible aquaculture: A guide for USAID staff and partners. University of Rhode Island/Coastal Resources Centre, Rhode Island, United State of America. 